the visit of Dr. Michele Bossi (Milano, Italy) giving a course (lectures and observations) on pulsating stars during April - June 1994. Although several students from Peru and Paraguay are now working/ studying elsewhere, the longer-term presence of astronomy in these two VLP counties is not yet secure. Commission 46 is proposing to the IAU Executive Committee that the VLP be continued as a more flexible program, Teaching for Astronomy Development (TAD), which takes into account the differing needs of various countries and allows some support of advanced students who are selected to study abroad and then return to their country. If approved, the new program will be announced widely. In common with the VLP, the goal is to enhance astronomy at selected host institutions on a long-term basis, using the influence and some financial support of the IAU.

\title{
THE WORLDWIDE DEVELOPMENT OF ASTRONOMY
}

\author{
A.H. Batten \\ Dominion Astrophysical Observatory, Victoria, BC Canada V8X 4M6 \\ E-mail: batten@dao.nrc.ca
}

The IAU Working Group for the Worldwide Development of Astronomy and Commission 46 have both aims and methods in common. The Workshop for secondary school teachers, organized in Pune, India, in connection with the 1993 IAU Regional Meeting, was similar in concept to many meetings organized by Commission 46 at previous General Assemblies, and benefitted greatly from the willing cooperation of many members of the Commission. I hope that such workshops will become regular features of Regional Meetings, and that Commission 46- which has the necessary experience and expertise-will take the lead in organizing them.

The Working Group, however, is concerned about the whole state of astronomy in different parts of the world, not just the teaching of astronomy-basic though that is. In the last twelve months I have travelled extensively, and my impressions of astronomy in various countries, while personal and incomplete, are first-hand. It is instructive to look at a map of the world on which the intensity of astronomical activity is portrayed. A Central American astronomer, M.C. Pineda de Carias, showed such a map at the UN/ESA Workshop in Nigeria last October. She simply coloured red all those countries with IAU members. I have updated her map and tried to introduce more detail by colour-coding for the number of IAU members and distinguishing between adhering and non-adhering countries. Even this more detailed map is over-simplified and therefore open to some objections; but however the map is constructed, it will clearly show that astronomers living in Europe (especially the western half), North America, and Japan are highly privileged. First, we have many colleagues whom we can meet fairly often. Second, despite our complaints about budget cutbacks, we have access to modern equipment, good 
libraries, and we can afford to travel. Third, we have all the conveniences of rapid communication- every institute has either fax or e-mail, both of which are very reliable.

In contrast, there are countries, mostly poor ones, with only one or two IAU members. Colleagues in this situation are obviously isolated. Not only do they have few contacts with their compatriots, but political, geographic and economic barriers often mean that contacts with colleagues elsewhere are few and difficult. Astronomy is low on the scale of their governments' priorities and is allotted so little money that no current journals at all can be bought. Finally, fax and e-mail are either nonexistent or unreliable. While this last disadvantage may be removed in the fairly near future, it is at present a real problem.

There are many countries between these extremes where colleagues have overcome the difficulties of relative isolation and made significant contributions to astronomy. The extremes serve to illustrate, however, how much some of us are privileged in comparison to colleagues for whom it is a major achievement to get a paper published at all. We can easily underestimate these colleagues because we so easily forget the difficulties under which they work. Programmes run by Commission 46, such as the ISYA and VLP are clearly valuable to our most isolated colleagues. Gifts of journals can also help. Don't wait until you retire to give away your lifetime collection - useful though such a gift can be. Try sending current volumes as they are completed. You can consult library copies, colleagues in many countries cannot.

\section{THE TEACHING OF ASTRONOMY: PSYCHOLOGICAL-EDUCATIONAL CONSIDERATION}

Joseph Nussbaum

Michlalah - Jerusalem College, P.O. Box 16078, Jerusalem, Israel

My task here is to present some thoughts regarding the teaching of introductory astronomy. These thoughts evolve from a broader framework currently prevailing amongst science education professionals. The main concern of this framework is finding ways of bridging and matching between the personal meaning of the learner and the accepted scientific meaning, regarding an area of knowledge.

What makes learning meaningful? When a person encounters a new body of knowledge and he/she attempts to acquire it, this knowledge will become 'meaningful' to him/her only when it is integrated with relevant knowledge already held by that person. Integrating (internalizing) new knowledge means establishing, in the student's mind, connections between elements of the new knowledge and related elements of existing knowledge. To become more meaningful, these connections should also constitute an extension and elaboration of the hierarchical structure of existing knowledge. Hierarchical structure, here, means that concepts, principles, 